\title{
NIETZSCHE, UMA REFLEXÃO A RESPEITO DO CURRÍCULO DE FILOSOFIA, EM SCHOPENHAUER COMO EDUCADOR
}

\author{
Thiago Presente Fedrigo
}

\section{RESUMO}

O cotidiano escolar apresenta uma infinidade de fenômenos aos pesquisadores que se interessam pela área educacional. Nessa medida, esse cotidiano é transformado em problema filosófico que é analisado pelos conceitos, criados pelos filósofos da tradição. Inserido no estágio curricular observacional, pude observar, no meio de tantos problemas encontrados, que alguns poderiam ser trabalhados via algum filósofo, dois deles foram: "as motivações do aluno no ensino médio nas aulas de filosofia"; "o ensino de filosofia através de problemas". Os dois problemas foram o que me fizeram pensar, como incentivar um aluno a estudar filosofia se o currículo esta se tornando enciclopédico? Vamos buscar encontrar alguns esclarecimentos no texto de Friedrich Nietzsche, "Schopenhauer como educador". Onde tratará da questão do ensino de filosofia na escola média alemã de sua época, que em sua visão a filosofia estaria sendo tradada com desprezo. Na medida em que sua crítica se direciona ao ensino "enciclopédico", é possível entender mais claramente sua indignação.

\section{INTRODUÇÃO}

O cotidiano escolar apresenta uma infinidade de fenômenos aos pesquisadores que se interessam pela área educacional. Nessa medida, esse cotidiano é transformado em problema filosófico que é analisado pelos conceitos, criados pelos filósofos da tradição. No relatório do Estágio de Observação, é necessário reportar o que se foi observado, tanto em relação à estrutura do estabelecimento, quanto às aulas observadas. Além disso, é preciso escolher um problema filosófico, que relacione o cotidiano observado e os problemas que foram encontrados durante o período do Estágio com o problema conceitual tratado por algum filósofo.

No meio de tantos problemas encontrados que pudessem ser trabalhados via algum filósofo, dois deles foram:"a motivação do aluno no ensino médio nas aulas de filosofia"; "o ensino de filosofia através de problemas". Os dois problemas foram o que me fizeram pensar, como incentivar um aluno a estudar filosofia se o currículo esta se tornando enciclopédico? Afinal, se o único incentivo que os alunos têm para adentrarem no universo da filosofia, é o de que o conteúdo vai cair na prova, ou no vestibular, e é preciso que se diga que foi uma tentativa das universidades, ao adicionarem a disciplina de filosofia em seus vestibulares, onde abarcam um programa que engloba quase toda a história da filosofia, para ser transpassado para um aluno no ensino médio em dois a três anos, é realmente estar a um passo ao currículo de filosofia se tornar meramente enciclopédico.

Ficamos então intrigados com uma questão, como ensinar filosofia no ensino médio? Ou melhor, como realmente ensinar de maneira significativa a filosofia para os jovens brasileiros? Vamos buscar encontrar alguns esclarecimentos no texto de Friedrich Nietzsche, "Schopenhauer como educador". Onde tratará da questão do 


\section{SEMINÁRIO DE PESQUISA EM CIÊNCIAS HUMANAS - SEPECH \\ Humanidades, Estado e desafios didático-científicos \\ Londrina, 27 a 29 de julho de 2016}

ensino de filosofia na escola média alemã de sua época, que em sua visão a filosofia estaria sendo tratada com desprezo. Na medida em que sua crítica se direciona ao ensino "enciclopédico", é possível entender mais claramente sua indignação. Afinal num programa de ensino onde os alunos são levados a aprender um sistema filosófico, suas doutrinações, e suas refutações somente para ser avaliado posteriormente para demonstrar o aprendizado, não levaria a um resultado diferente se não o de os alunos decorarem tudo na véspera da prova e logo no dia seguinte já esquecerem tudo sobre o que se foi testado, claramente se expõe aqui uma questão de desprezo à filosofia.

À luz dessas questões e tendo como escopo definido, a reflexão contida no relatório abordara o tema, do currículo de filosofia no ensino médio.

\section{NIETZSCHE, UMA REFLEXÃO A RESPEITO DO CURRÍCULO DE FILOSOFIA, EM SCHOPENHAUER COMO EDUCADOR.}

Schopenhauer tem suma influência na obra de Nietzsche, não tanto pela sua filosofia, mas sim pelas suas ideias - em relação às quais este, desde o início, manteve uma posição de aceitação, e também de recusa, de crítica - mas pela forma de ser filósofo e se fixar como tal, tendo à margem da Filosofia oficial do Estado prussiano e também a indiferença a seus contemporâneos. Na obra Schopenhauer como educador podemos ver o grande destaque que o autor dá ao devir. Como ele mesmo diz em seu livro Ecco homo: “(...) no Schopenhauer como educador está escrita minha história íntima, meu devir. Acima de tudo minha promessa" (NIETZSCHE, 2006, p. 74). E também emprega a terminologia schopenhaueriana do gênio, como assegura Rosa Dias (1999, p. 68), "Nietzsche emprega a terminologia de Schopenhauer sobre o gênio, para criar a ideia do próprio Schopenhauer como gênio". Percebe-se aí então, uma diferença entra a concepção de gênio de Schopenhauer, e de Nietzsche. Para Schopenhauer o gênio, nasce gênio, dotado de uma inteligência superior aos homens comuns, como um dom natural. Já para Nietzsche o gênio se faz gênio, por meio de sua vontade, as condições que se tornaram ligadas ao seu desenvolvimento, lhe proporcionaram o florescimento de um gênio. Para Nietzsche, "a criação do gênio [...] é o objetivo de toda cultura" (NIETZSCHE, 2003b, p. 158).

$\mathrm{O}$ projeto de Bildung perpassa a ideia de gênio prefigurada na imagem de educador. Podemos dizer que o projeto da Bildung nietzschiana em Schopenhauer como educador é construído através por um movimento fisiológico da experiência entre o mestre educador e o formando. Ou seja: "o ideal que educa" (NIETZSCHE, 2003b, p. 175). No caso, o método pedagógico é, exatamente, a exemplaridade do educador composta de características singulares: honestidade, serenidade, constância, discurso correto, rude e benevolente, companheiro no sofrimento, extraordinário e insuportável. Analisando estas características singulares poderemos ver de que forma, se tem uma concepção pedagógica de formação.

A honestidade, refere-se aquela para consigo mesma, "de falar e escrever por si mesmo" (NIETZSCHE, 2003b, p. 150). E não aquela que visa agradar a uma maioria e ir de encontro a uma lógica estatal. $\mathrm{O}$ discurso correto, rude e benevolente, expressa a fala e a escrita de modo original, com desenvoltura e naturalidade. Ou seja, escrever seus próprios pensamentos, independente da lógica vigente ou da intenção de agradar uma maioria. A honestidade como uma condição formativa, tem grande importância, pois colabora para a afirmação da existência, apesar do isolamento, e da indiferença dos 


\section{SEMINÁRIO DE PESQUISA EM CIÊNCIAS HUMANAS - SEPECH \\ Humanidades, Estado e desafios didático-científicos \\ Londrina, 27 a 29 de julho de 2016}

alemães de sua época. Assim, relata Nietzsche, (2003b, p. 153) "para salvaguardar sua própria existência, ele tinha de defender a todo custo sua filosofia contra a indiferença dos seus contemporâneos".

A serenidade por sua vez, é concebida ao pensador autêntico, que o deixa alegre e tranquilo, "sem mãos trêmulas, sem olhares sufocados, mas com segurança e simplicidade, com coragem e vigor, talvez com algo de cavalheiresco e duro, mas sempre como vencedor" (NIETZSCHE, 2003b, p. 149). A serenidade é vista como concepção pedagógica, pois possibilita ao homem moderno vencer o medo da verdade que acompanha durante sua vida. Nesse sentido, a serenidade do pensamento, nos permite entender que o quadro geral da vida, só se entende por meio dela mesma. Segundo Nietzsche, a serenidade que devem possuir os seres que pensam é alcançada "senão lá onde há vitória", quando há consciência de que o "conteúdo dela pode bem ser tão terrível e grave quanto o problema mesmo da existência" (NIETZSCHE, 2003b, p. 149).

Por ultimo, trataremos da constância, que lida com a nostalgia do gênio que é acometido, por abdicar do seu próprio querer, da sua própria vontade do conhecimento

para si, para atingir o objetivo maior, de trabalhar em favor do gênio e da cultura. Como esclarece Nietzsche :

Se aplicarmos estes termos a Schopenhauer, tocaremos no terceiro e mais notável perigo no qual ele viveu, e que estava oculto em toda a estrutura e toda a ossatura do seu ser. Todo homem encontra normalmente em si um limite dos seus dons, assim como do seu querer moral, e este limite o enche de nostalgia e melancolia. [...] Assim, ele sabia que tinha uma parte do seu ser satisfeita e cumprida, sem desejo, certo da força que possuía - assim, consciente de ser uma realização vencedora, carregava sua vocação com grandeza e dignidade. Uma nostalgia impetuosa vivia na outra metade do seu ser. Compreendemos isto ao ouvi-lo dizer que ele se afastava com um olhar pesaroso de um retrato de Rancé, o grande fundador da Ordem dos Trapistas, murmurando estas palavras: "Eis aí a obra da graça". Pois o gênio aspira cada vez mais à santidade que, a partir do seu posto de observação, ele viu mais longe e mais claro do que qualquer outro homem, lá onde o conhecimento e o ser se reconciliam, lá onde dominam a paz e a negação do querer, e até esta outra margem da qual falam os hindus. (2003b, p. 158-159).

Existe uma constância no pensamento de que é preciso trabalhar para além de uma vontade e um querer particulares e individuais e buscar o objetivo maior que é "progredir uma cultura em gestação e a criação do gênio" (NIETZSCHE, 2003b, p. 158). Desse modo, o projeto da Bildung nietzschiana não é, de forma alguma, uma proposta individualista e mesquinha. É essencial entender que a responsabilidade para o formar-se deve partir de cada um singularmente, mas para chegar ao compromisso maior que é o desenvolvimento do gênio e o criação da cultura. Como afirma Nietzsche, as ofensivas que ameaçaram Schopenhauer, ameaçam a todos nós, assim como cada um de nós traz consigo uma subjetividade produtiva. Isto é, é a nossa individualidade que 


\section{SEMINÁRIO DE PESQUISA EM CIÊNCIAS HUMANAS - SEPECH \\ Humanidades, Estado e desafios didático-científicos \\ Londrina, 27 a 29 de julho de 2016}

nos possibilita o enfrentamento das adversidades - "o homem tal como propriamente é, e tal como ele é único e original em cada movimento de seus músculos, e mais ainda, que ele é belo e digno de consideração segundo a estrita coerência da sua unicidade" (NIETZSCHE, 2003b, p. 139).

Nietzsche exalta a grandeza de seu mestre na seguinte passagem:

Esta é a sua grandeza. Ter-se colocado de frente ao quadro da vida como de frente a um todo, para interpretá-lo como um todo; enquanto as cabeças mais perspicazes não conseguem libertar-se dos erros a que esta interpretação se possa alcançar só analisando minuciosamente as cores e a matéria sobre as quais este quadro foi pintado (NIETZSCHE, 1999, p. 9).

Nietzsche justifica a escolha de Schopenhauer como seu mestre, dizendo que ele possuía três qualidades fundamentais, a sinceridade, a serenidade e a firmeza, qualidades que afastavam Schopenhauer da imagem do erudito. Ele não quis seguir o sistema, e isso causou profunda admiração em Nietzsche.

O argumento principal de Schopenhauer como educador consiste no problema de que cada indivíduo deveria eleger um filósofo como educador, assim como o Nietzsche fez com Schopenhauer. Nesse sentido o autor defende um tipo de educação não escolar, uma autoeducação, que seria um processo de libertação existencial e que tem como objetivo final atingir a maturidade, e a harmonia entre os seres humanos. Assim como em suas próprias palavras Nietzsche prossegue:

[...] a sua verdadeira existência, de fato, não está escondida dentro de você, mas muito acima de você ou daquilo que considera o seu eu. Os seus verdadeiros educadores e mestres revelam o sentido originário e a matéria fundamental do seu ser, algo que não se pode absolutamente educar nem formar, mas em todo caso é de difícil acesso por estar amarrado, paralisado: os seus educadores não podem ser nada mais que seus libertadores (NIETZSCHE, 1999, p. 3).

Retomando a reflexão a respeito do currículo anteriormente adiada na introdução, podemos prosseguir tendo em vista a formação de um eixo de currículos que seriam possíveis de serem aplicados no contexto filosófico vivido nas salas de aula. Podemos imaginar ao menos três variações em torno dos quais podemos pensar um currículo de Filosofia: uma variação histórica, uma variação temática, e uma variação problemática.

O primeiro baseia-se na organização dos conteúdos a serem ensinados seguindo uma cronologia histórica. O problema é evidente, e já especificado, um currículo como esse, torna-se fatalmente um currículo enciclopédico, dando enfoque muito mais em datas, nome de filósofos, pensamentos, do que no que realmente importaria e acrescentaria.

No segundo, são eleitos temas, como liberdade, morte, justiça, ou qualquer outro tema de natureza filosófica. São apresentados em forma de temas para torná-los mais 


\section{SEMINÁRIO DE PESQUISA EM CIÊNCIAS HUMANAS - SEPECH \\ Humanidades, Estado e desafios didático-científicos \\ Londrina, 27 a 29 de julho de 2016}

próximo à realidade vivida pelos alunos. Em termos de organização, essa abordagem me parece mais apropriada que a anterior.

Por fim na terceira alternativa, foi o que encontrei que mais se assemelha ao currículo adotado pelo Colégio Nilo Cairo, e que foi possível constatar em minhas 10 semanas de observação no Colégio, e que onde sem a formação adequada de um professor de filosofia não seria possível, acredito que esta abordagem abarca as duas outras anteriores, apesar de que um currículo já muito conteudista, a filosofia é vista apenas como um conteúdo a mais. Os conteúdos são organizados em torno dos problemas tratados pela filosofia, que recortam os temas e podem ser abordados historicamente. Toma a filosofia como uma ação, o movimento que motiva e impulsiona o filosofar, refletir o problema.

Apesar de toda a reflexão a respeito do currículo escolar, ainda penso que o cotidiano que o aluno vive na escola do ensino médio gira em torno de conteúdos que não criam significado relevante no aluno, e sim meramente algo que vai ser necessário para ele como aluno, passar de ano, ou adentrar em alguma universidade. Ou seja, estamos vivendo mesmo no precipício em que Nietzsche estava a passar por sua época, ou seria apenas um momento de transição da filosofia na educação para algo que Nietzsche chama de uma educação não escolar, ou uma autoeducação? Algumas certas palavras de Paulo Freire que encaixariam bem no contexto:

\footnotetext{
É necessário acreditar na possibilidade de ir além do amanhã, sem ser ingenuamente idealista, É necessário perseguir as utopias, como relação dialética entre denunciar o presente e anunciar o futuro, É necessário antecipar o amanhã pelo sonho de hoje. O sonho é um sonho possível ou não? Se for menos possível, trata-se para nós, de sabermos como torná-lo mais possível. (FREIRE, 2000, p. 35).
}

Penso que a melhor forma de lidarmos com esse problema, é o fato de encararmos a situação da filosofia nas escolas nos dias de hoje, Nietzsche sintetiza em algumas palavras o que temos passado, em Schopenhauer como educador:

E, por fim, em que neste mundo importa a nossos jovens a história da filosofia? Será que eles devem, pela confusão das opiniões, ser desencorajados de terem opiniões? Será que devem ser ensinados a participar do coro de júbilo: como chegamos tão esplendidamente longe? Será que, porventura, devem aprender a odiar ou desprezar a filosofia? Quase se poderia pensar este último, quando se sabe como os estudantes têm de se martirizar por causa de suas provas de filosofia, para imprimir as ideias mais malucas e mais espinhosas do espírito humano, do lado das mais grandiosas e mais difíceis de captar, em seu pobre cérebro. A única crítica de uma filosofia que é possível e que, além disso, demonstra algo, ou seja, ensaiar se se pode viver segundo ela, nunca foi ensinada em universidades: mas sempre a crítica de palavras com palavras. E agora pense se em uma cabeça juvenil, sem muita experiência da vida, em que cinquenta sistemas em palavras e cinquenta críticas desses sistemas são guardados juntos e misturados - que aridez, que selvageria, que escárnio, quando se trata de uma educação para a filosofia! Mas, de fato, todos reconhecem que não se educa para ela, mas para uma prova de filosofia: cujo resultado, sabiamente e de hábito, é quem sai dessa prova - ai, dessa provação! - 


\section{SEMINÁRIO DE PESQUISA EM CIÊNCIAS HUMANAS - SEPECH \\ Humanidades, Estado e desafios didático-científicos \\ Londrina, 27 a 29 de julho de 2016}

confessa a si mesmo com um profundo suspiro: "Graças a Deus que não sou filósofo, mas cristão e cidadão do meu Estado!"(NIETZSCHE, 2003, p. 79)

E se esse suspiro profundo fosse justamente o escopo do Estado, e a "educação para a filosofia", em vez de conduzir a ela, servisse somente para afastar da filosofia?

\section{REFERENCIAS BIBLIOGRÁFICAS:}

FREIRE, Paulo. Pedagogia da Indignação: cartas pedagógicas e outros escritos. São Paulo: UNESP, 2000.

NIETZSCHE, F. W. Schopenhauer como educador. In: NIETZSCHE, F. W. Escritos sobre educação. Trad. Noéli C. M. Sobrinho. Rio de Janeiro/São Paulo: PUCRio/Loyola, 2003b.

NIETZSCHE, F. W. Ecce Homo: como se chega a ser o que se é. Trad. Antonio Carlos Braga. São Paulo: Escala. 2006.

NIETZSCHE, Friedrich. Considerações extemporâneas. Obras incompletas. Coleção Os Pensadores: seleção de textos de Gérard Lebrun. Tradução e notas de Rubens Rodrigues Torres Filho. São Paulo: Editora Nova Cultural, 1999.

DIAS, R. M. Nietzsche e a questão do gênio. In: BARRANECHEA, M.; PIMENTA NETO (Orgs.). Assim falou Nietzsche. Rio de janeiro: Sete Letras, 1999.

LIMA, S.C.F. A concepção de formação em Nietzsche: Uma leitura de "Schopenhauer como educador". Disponível em: https://www.metodista.br/revistas/revistaunimep/index.php/comunicacao/article/view/1139/1085.Acesso dia : 31/07/2015

WEBER, J.F. Singularidade e formação (Bildung) em Schopenhauer como educador de Nietzsche. Disponível em: http://www.revistas.usp.br/ep/article/view/28191. Acesso dia : 31/07/2015 